\title{
Tratamiento de la hepatitis C crónica en pacientes de edad avanzada con enfermedad renal crónica: revisión estructurada
}

\section{Treatment of chronic hepatitis C in elderly patients with chronic kidney disease: a structured review}

\author{
Mónica Ledezma-Morales, ${ }^{1}$ Pedro Amariles. ${ }^{2}$
}

\footnotetext{
Química farmacéutica. Magíster en Investigación y Uso Racional del Medicamento. Estudiante de Doctorado en Ciencias Farmacéuticas y Alimentarias, Universidad de Antioquia. Medellín, Colombia.

2 Químico farmacéutico. Doctor en Farmacología, Universidad de Antioquia. Medellín, Colombia.

Correspondencia: Mónica Ledezma-Morales. Correo: monica.ledezma@udea.edu.co.

Fecha recibido: $\quad 13-12-17$

Fecha aceptado: 20-01-18
}

\begin{abstract}
Resumen
La hepatitis $\mathrm{C}(\mathrm{HC})$ es un problema de salud pública a nivel mundial, con alta prevalencia en pacientes mayores de 50 años. Esta población es más propensa a sufrir enfermedad renal crónica (ERC), tanto por la infección por el virus de la HC como por su edad y múltiples comorbilidades. Los pacientes con ERC en estadios 4 o 5 pueden ser una población de mayor complejidad farmacoterapéutica, por su variabilidad farmacológica y por la limitada información de seguridad y eficacia de los nuevos antivirales en ese grupo de pacientes. Objetivo: sistematizar información de dosificación de medicamentos para la HC crónica, a partir de estudios o reportes que incluyeran pacientes de edad avanzada con ERC. Materiales y métodos: revisión estructurada en PubMed/Medline con los términos: "Hepatitis C", "Aged" y "Renal Insufficiency"; artículos publicados entre 1 de agosto de 2012 y 1 de agosto de 2017, en inglés o español, estudios realizados en humanos, con acceso a texto completo. Resultados: se identificaron 83 artículos, de los cuales se seleccionaron 14; además, se incluyeron 4 manuscritos referenciados en las publicaciones revisadas. Se estructuró un cuadro con información de dosificación de antivirales para el tratamiento de la $\mathrm{HC}$ en pacientes de edad avanzada con ERC. Discusión: Se presenta información sobre el ajuste de dosis de los medicamentos antivirales utilizados para la $\mathrm{HC}$ crónica, en pacientes de edad avanzada y ERC, que podría favorecer los procesos de prescripción y seguimiento para contribuir con la efectividad y seguridad de dichos fármacos en esta población.
\end{abstract}

\section{Palabras clave}

Hepatitis C, anciano, enfermedades renales, antivirales.

\begin{abstract}
Hepatitis $\mathrm{C}(\mathrm{HC})$ is a public health problem worldwide and has especially high prevalence in patients over 50 years of age. This population is more prone to suffer from chronic kidney disease (CKD) due to HC infections as well as to age and multiple comorbidities. Those with CKD stages 4 or 5 constitute a population of greater pharmacotherapeutic complexity due to pharmacological variability and limited information on the safety and efficacy of the new antivirals for this group of patients. Objective: This article systematizes information about medications and proper dosages for treating chronic $\mathrm{HC}$ and is based on studies and reports that include elderly patients with CKD. Materials and method: This is a structured review of studies carried out in humans with access to full text published between 01/08/2012 and 01/08/2017 in English or Spanish found in PubMed/ Medline using the terms: "Hepatitis C", "Aged", and "Renal Insufficiency". Results: Eighty-three articles were identified, fourteen of which were selected. In addition, four manuscripts referenced in those publications were included. A table with antiviral dosing information for treatment of $\mathrm{HC}$ in elderly patients with CKD was structured. Discussion: We present information on adjustment of dosages of antiviral drugs used for chronic $\mathrm{HC}$ in elderly patients and CKD. This could favor prescription and monitoring thereby contributing to the effectiveness and safety of these drugs in this population.
\end{abstract}

\section{Keywords}

Hepatitis C, elderly, kidney diseases, antivirals. 


\section{INTRODUCCIÓN}

La hepatitis $\mathrm{C}$ (HC) es un enfermedad infecciosa causada por el virus de la hepatitis $\mathrm{C}$ (VHC), la cual es considerada un problema de salud pública por la Organización Mundial de la Salud (OMS), debido a que: afecta el $2 \%-3 \%$ de la población mundial; se asocia con una alta morbimortalidad, puesto que entre el 70\%-90\% de los pacientes infectados progresa a enfermedad hepática crónica como cirrosis y carcinoma hepatocelular ( $\mathrm{CHC}$ ), en algunos casos asociado con trasplante hepático $(1,2)$; y afecta a poblaciones vulnerables y en gran parte desatendidas como los usuarios de drogas inyectables y personas con inadecuada asistencia sanitaria.

La HC crónica también se relaciona con manifestaciones extrahepáticas, incluidos trastornos dermatológicos, reumatológicos, hematológicos y renales (3). Esta última puede manifestarse con proteinuria o con una disminución de la tasa de filtración glomerular (TFG) e incluso enfermedad renal crónica (ERC) (3-8). El desarrollo de ERC por el VHC puede estar relacionado con el desarrollo de glomerulonefritis, mediada por la acumulación de crioglobulinas, complejos inmunes de anticuerpos contra el VHC o deposición de amiloide $(3,5,9,10)$.

Por su parte, los pacientes en hemodiálisis (HD) tienen mayor riesgo de adquirir la infección por el VHC, debido a la exposición repetida a patógenos transmitidos por la sangre, la necesidad de transfusiones, la duración de la diálisis, la necesidad de acceso intravenoso y la manipulación del catéter $(11,12)$. Esto resulta en una alta prevalencia de infección por VHC en pacientes con ERC terminal (1217 ), que en Colombia es del 53\% (18).

A nivel mundial, la prevalencia de $\mathrm{HC}$ es más alta en pacientes mayores de 50 años (19) y, en Colombia, la mayor proporción de casos notificados corresponde a los pacientes con edades iguales o superiores a 65 años (20). Esta población es más propensa a presentar enfermedades como hipertensión arterial, dislipidemia, diabetes mellitus, enfermedad cardiovascular y obesidad, que constituyen factores de riesgo adicionales para el desarrollo de ERC (5, 21,22). Así mismo, las alteraciones fisiológicas típicas de la edad, principalmente de los órganos encargados del metabolismo y la excreción de fármacos (23), suscitan una variabilidad farmacológica que los hace más vulnerables a los eventos adversos a medicamentos (EAM) (24). Por tanto, los pacientes de edad avanzada, generalmente con ERC y con HC crónica, constituyen una población con complejidad farmacoterapéutica mayor. Más aún, las opciones de tratamiento para la $\mathrm{HC}$ en pacientes con ERC estadios $4 \mathrm{o}$ 5 son limitadas, debido a la pobre tolerancia y baja efectividad de las terapias convencionales con interferón (IFN) y ribavirina (RBV) $(13,17,25)$; y a la información limitada sobre la seguridad y eficacia de los actuales regímenes de antivirales de acción directa (AAD), dado que no se han evaluado adecuadamente en pacientes con ERC durante los ensayos clínicos $(12,26)$.

Por lo anterior, es necesario disponer de información sobre la dosificación, efectividad y seguridad de los antivirales para la $\mathrm{HC}$, en los pacientes de edad avanzada con ERC, con el fin de lograr los mejores resultados en salud posibles y evitar EAM. En consecuencia, el objetivo de esta revisión fue sistematizar la información de dosificación de medicamentos para la $\mathrm{HC}$ crónica a partir de estudios o reportes que incluyeran pacientes de edad avanzada con ERC.

\section{MATERIALES Y MÉTODOS}

Se realizó una revisión en PubMed/Medline utilizando la estrategia de búsqueda: "Hepatitis C"[Mesh] AND "Aged"[Mesh] AND "Renal Insufficiency"[Mesh]. Con filtros para artículos publicados entre el 1 de agosto de 2012 y 1 de agosto de 2017, en inglés o español, estudios realizados en humanos, con acceso a texto completo. Se incluyeron artículos de estudios y reportes, cuya muestra incluyera pacientes de edad avanzada con ERC y HC. Los criterios de exclusión fueron: artículos sin mención del manejo farmacológico de la HC en ERC, artículos con información incompleta de dosis y artículos relacionados con medicamentos retirados por la Food and Drug Administration (FDA), la European Medicines Agency (EMA) o el Instituto Nacional de Vigilancia de Medicamentos y Alimentos de Colombia (INVIMA). La búsqueda se complementó con publicaciones consideradas relevantes, referenciadas en los artículos encontrados.

Los artículos incluidos se evaluaron de forma pareada. Para ello, se revisaron los títulos y resúmenes de todos los artículos identificados para decidir su elegibilidad. Los artículos seleccionados se analizaron conjuntamente y, por consenso, se definió su inclusión.

La información se estructuró en una base de datos con la siguiente información: medicamento evaluado, genotipo del VHC, TFG del (los) paciente(s) estudiado(s), estadio de la ERC, dosis utilizada e información sobre eliminación por diálisis, eficacia/efectividad (reportada como respuesta viral sostenida y definida como carga viral indetectable a las 12 o 24 semanas después del fin del tratamiento [respuesta virológica sostenida -RVS- 12 o RVS24]), EAM, tipo de estudio y referencia.

Los resultados obtenidos se compararon con las dosificaciones para los pacientes con función renal normal (Tabla 1) y con las recomendaciones de ajuste de dosis presentadas 
Tabla 1. Dosificación de medicamentos para tratar la HC crónica en pacientes con función renal normal

\begin{tabular}{ll}
\hline \multicolumn{1}{c}{ Medicamento } & \multicolumn{1}{c}{ Dosis } \\
\hline Elbasvir/grazoprevir & $50 / 100 \mathrm{mg}$ cada 24 horas \\
Ombitasvir/paritaprevir/ritonavir & $25 / 150 / 100 \mathrm{mg}$ cada 24 horas \\
Dasabuvir & $250 \mathrm{mg}$ cada 12 horas \\
Sofosbuvir & $400 \mathrm{mg}$ cada 24 horas \\
Simeprevir & $150 \mathrm{mg}$ cada 24 horas \\
Ledipasvir/sofosbuvir & $90 / 400 \mathrm{mg}$ cada 24 horas \\
Daclatasvir & $60 \mathrm{mg}$ cada 24 horas \\
Asunaprevir & $100 \mathrm{mg}$ cada 12 horas \\
RBV & En combinación con PEG-IFN a2b: según el peso: $800-1400 \mathrm{mg}$ cada día en dosis divididas \\
& En combinación con IFN a2b: según el peso: <75 kg: $1000 \mathrm{mg}$ cada día $0 \geq 75 \mathrm{~kg}: 1200 \mathrm{mg}$ cada día, \\
PEG-IFN a2a & administrada en dosis divididas \\
PEG-IFN a2b & $180 \mu \mathrm{mg}$ una vez a la semana \\
\hline
\end{tabular}

Información extraída de los insertos de los medicamentos. PEG-IFN: interferón pegilado.

en dos bases de datos utilizadas con frecuencia por médicos y farmacéuticos para la consulta de posologías: UpToDate ${ }^{\oplus}$ y Micromedex ${ }^{\oplus}$.

\section{RESULTADOS}

Se identificaron 83 artículos, de los cuales se incluyeron 14. Adicionalmente, se consideraron relevantes 4 artículos referenciados en las publicaciones revisadas (Figura 1).

El 38,9\% de los artículos correspondieron a estudios observacionales analíticos, seguidos de estudios observacionales descriptivos $(33,3 \%)$ y estudios experimentales $(27,8 \%)$.

Se identificó información de 7 estrategias terapéuticas con $\mathrm{AAD}$ de segunda generación (elbasvir/grazoprevir, paritaprevir/ombitasvir/ritonavir, dasabuvir, sofosbuvir, simeprevir, daclatasvir y asunaprevir), de PEG-IFN y RBV. Los estudios y reportes revisados contenían información de la utilización de medicamentos anti-VHC en pacientes entre los 18 y 79 años de edad.

En la Tabla 2 se presenta un resumen de las recomendaciones de dosificación según la función renal, tanto de las bases de datos (UpToDate ${ }^{\circledast}$ yicromedex ${ }^{\circledast}$ ) como de la presente revisión. En la Tabla 3 se presenta la información completa obtenida de la revisión.

\section{DISCUSIÓN}

El tratamiento antiviral se considera imprescindible en los pacientes con HC crónica, para prevenir las complicacio- nes y mejorar el pronóstico, más aún cuando hay evidencia de manifestaciones extrahepáticas como las alteraciones renales $(13,25)$, que pueden requerir diálisis o trasplante renal (TR). Adicionalmente, no tratar a pacientes que han adquirido el VHC mediante la diálisis y que esperan TR puede permitir la progresión de la $\mathrm{HC}$ hasta $\mathrm{CHC}$ (con necesidad de trasplante hepático) y afectar negativamente la asignación y los recursos de trasplante de órganos (27). Por tanto, no tratar la infección por VHC en pacientes con ERC disminuye la supervivencia del paciente y del injerto (en el caso de pacientes trasplantados o candidatos a trasplante), y aumenta la mortalidad $(8,12-14,28,29)$.

Esta revisión permitió ampliar la información de dosificación de medicamentos antivirales para el VHC en pacientes de edad avanzada con ERC, la cual fue estructurada en una tabla, que puede ser de utilidad para los profesionales de la salud implicados en la prescripción y el seguimiento de dichos pacientes. Se encontró información que no estaba disponible en bases de datos de consulta frecuente (UpToDate ${ }^{\circledast}$ y Micromedex ${ }^{\circledR}$ ), como es el caso de las dosis de paritaprevir/ombitasvir/ritonavir y dasabuvir en pacientes con HD y diálisis peritoneal (DP), al igual que la posología de sofosbuvir y simeprevir en pacientes con TFG menor de $30 \mathrm{~mL} / \mathrm{min}$, HD o DP. De igual forma, se confirma la información existente en UpToDate ${ }^{\circledast}$ y Micromedex ${ }^{\circledast}$ sobre daclatasvir, elbasvir/grazoprevir, PEG-IFN y RBV; y se soporta la información sobre el uso de asunaprevir en HD, hallada en UpToDate ${ }^{\circledast}$ y de la cual no se disponía información en Micromedex ${ }^{\odot}$ debido a que no está aprobado en Estados Unidos. 


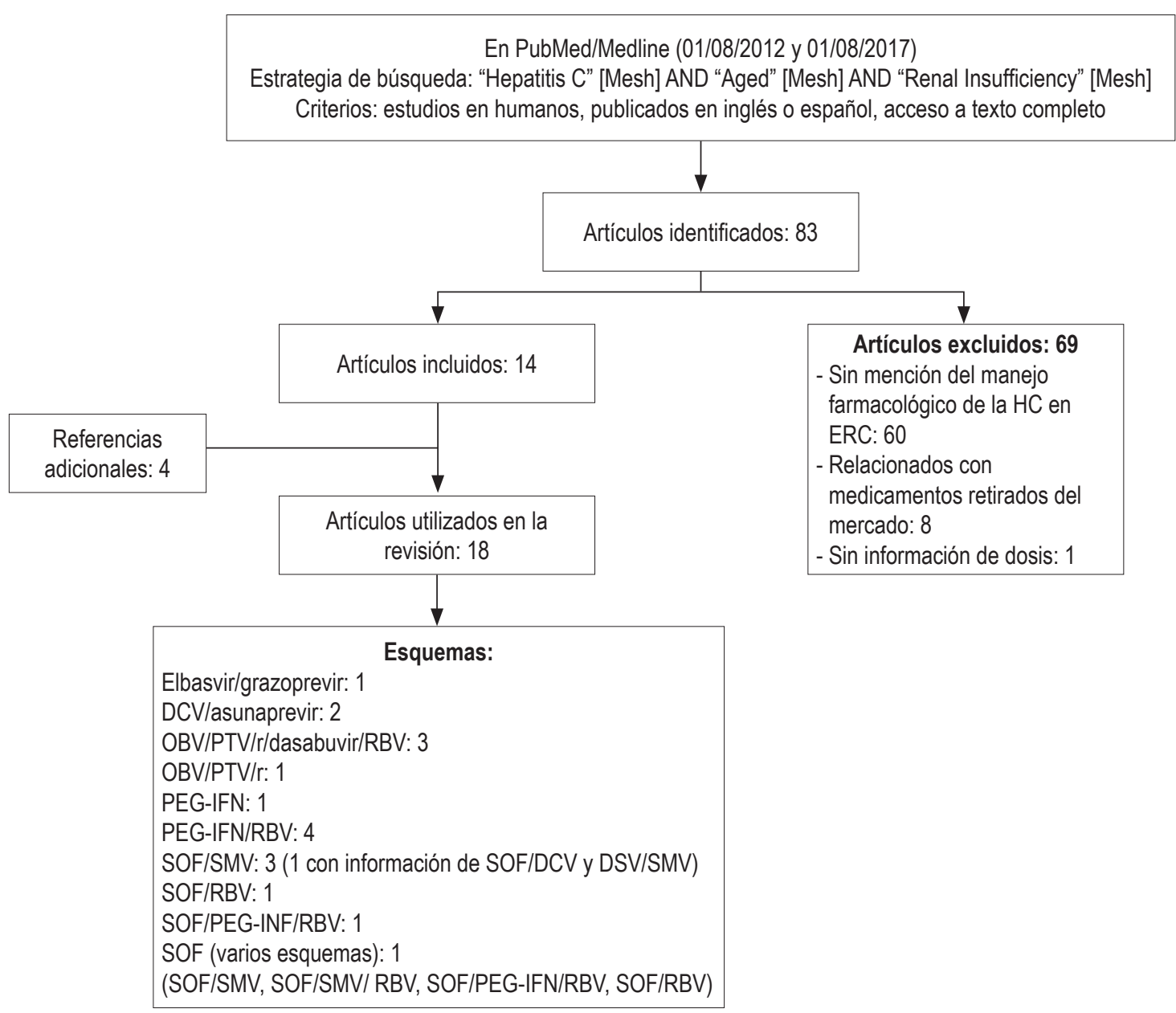

Figura 1. Flujograma general de la revisión. DCV: daclatasvir; OBV: ombitasvir; PTV: paritaprevir; r: ritonavir; SMV: simeprevir; SOF: sofosbuvir.

Dentro de las dosis que presentaban mayor variabilidad, entre los estudios y reportes están las de RBV. 3 de los 5 estudios que reportaron su utilización en pacientes con HD mostraron diferencias entre las dosis utilizadas comparadas con la información del inserto (30) y de las bases de datos de referencia $(31,32)$, en las que se recomienda una dosis de $200 \mathrm{mg}$ al día. Por ejemplo, Hundemer y colaboradores (33) utilizaron una dosis de RBV de $200 \mathrm{mg}$ cada 12 horas en 1 paciente que también recibió sofosbuvir a dosis plenas, dicho paciente presentó anemia que requirió el uso de eritropoyetina durante el tratamiento antiviral; sin embargo, no requirió el ajuste ni la suspensión de los medicamentos utilizados. Otros autores, como Sperl y colaboradores (34), utilizaron dosis reducidas de RBV de 200 a 400 mg semanales, en combinación con PEF-IFN a2a y 73,9\% (17 de 23 tratados) alcanzaron RVS a las 24 semanas; solo 9 pacientes presentaron empeoramiento de la anemia, con requerimiento de eritropoyetina ( 8 pacientes) y transfusión (1 paciente). Así mismo, Hidalgo y colaboradores (28), aunque iniciaron tratamiento con RBV 200 mg al día junto con PEG-IFN, tuvieron que disminuir la dosis de la RBV a 200 mg cada 48 horas debido a una disminución de la hemoglobina en la paciente; adicionalmente, fue necesario aumentar la dosis de darboeritropoyetina.

Con el sofosbuvir, también se presentaron diferencias entre las dosificaciones utilizadas en pacientes con TFG $<15 \mathrm{~mL} / \mathrm{min} / 1,73 \mathrm{~m}^{2}$, en HD o DP, explicadas por la falta de información en el inserto del medicamento y las precauciones por su excreción renal. Beinhardt y colaboradores (9), Hundemer y colaboradores (33), Nazario y colaboradores (27) y Saxena y colaboradores (35) utilizaron dosis de sofosbuvir de $400 \mathrm{mg}$ al día en pacientes con TFG $<15$ $\mathrm{mL} / \mathrm{min} / 1,73 \mathrm{~m}^{2}$ o en $\mathrm{HD}$; mientras que Bhamidimarri y colaboradores (36) emplearon dosis de $400 \mathrm{mg}$ cada 48 
Tabla 2. Recomendaciones de ajuste de dosis de medicamentos para pacientes con $\mathrm{HC}$ y ERC

\begin{tabular}{|c|c|c|c|c|c|}
\hline \multirow[t]{2}{*}{ Medicamento } & \multirow[t]{2}{*}{ GNT } & \multirow[t]{2}{*}{ TFG } & \multicolumn{3}{|r|}{ Recomendaciones } \\
\hline & & & Uptodate (31) & Micromedex (32) & Presente revisión \\
\hline \multirow[t]{2}{*}{$\begin{array}{l}\text { Elbasvir/ } \\
\text { grazoprevir }\end{array}$} & \multirow[t]{2}{*}{$\begin{array}{l}1 \mathrm{a}, \\
1 \mathrm{~b}, 4\end{array}$} & $>50 \mathrm{~mL} / \mathrm{min}$ & No es necesario ajustar la dosis. & $\begin{array}{l}\text { No es necesario ajustar } \\
\text { la dosis. }\end{array}$ & $50 / 100 \mathrm{mg}$ cada 24 horas (no requiere ajuste) (29) \\
\hline & & $\begin{array}{l}\leq 50 \mathrm{~mL} / \\
\text { min, ERCT } \\
\text { incluida } \mathrm{HD}\end{array}$ & $\begin{array}{l}\text { No es necesario ajustar la dosis. No } \\
\text { removida por HD. }\end{array}$ & $\begin{array}{l}\text { No es necesario ajustar } \\
\text { la dosis. }\end{array}$ & $50 / 100$ mg cada 24 horas (no requiere ajuste) (29) \\
\hline \multirow{2}{*}{$\begin{array}{l}\text { Ombitasvir/ } \\
\text { paritaprevir/ } \\
\text { ritonavir }\end{array}$} & \multirow[t]{2}{*}{4} & $\geq 15 \mathrm{~mL} / \mathrm{min}$ & No es necesario ajustar la dosis. & $\begin{array}{l}\text { No es necesario ajustar } \\
\text { la dosis. }\end{array}$ & $25 / 150 / 100$ mg cada 24 horas (no requiere ajuste) (37-39) \\
\hline & & Diálisis & $\begin{array}{l}\text { No se proporcionan ajustes de dosis } \\
\text { en el etiquetado del fabricante (no ha } \\
\text { sido estudiado). }\end{array}$ & $\begin{array}{l}\text { No es necesario ajustar } \\
\text { la dosis. }\end{array}$ & $\begin{array}{l}\text { HD: } 25 / 150 / 100 \text { mg cada } 24 \text { horas (no requiere ajuste). Los datos de la eliminación por } \\
\text { HD son limitados; sin embargo, sugieren que estos medicamentos no son extraídos por } \\
\text { HD. Se puede administrar en cualquier momento -antes o después- de la HD (39) } \\
\text { DP: Se han utilizado dosis de } 12,5 / 75 / 50 \text { mg cada } 24 \text { horas. La eliminación por DP es } \\
\text { menor que la observada con la HD convencional. Por la naturaleza continua de la DP, } \\
\text { la eliminación semanal acumulada es similar a la observada con HD intermitente (26) }\end{array}$ \\
\hline \multirow[t]{2}{*}{ Dasabuvir } & \multirow[t]{2}{*}{$1 \mathrm{a}, 1 \mathrm{~b}$} & $\geq 15 \mathrm{~mL} / \mathrm{min}$ & No es necesario ajustar la dosis. & $\begin{array}{l}\text { No es necesario ajustar } \\
\text { la dosis. }\end{array}$ & 250 mg cada 12 horas (no requiere ajuste) $(37,39)$ \\
\hline & & Diálisis & $\begin{array}{l}\text { No hay ajuste de dosis recomendado } \\
\text { por el fabricante (no ha sido } \\
\text { estudiado). }\end{array}$ & Sin datos & $\begin{array}{l}\text { HD: } 250 \text { mg cada } 12 \text { horas (no requiere ajuste). Los datos de la eliminación por HD } \\
\text { son limitados; sin embargo, sugieren que estos medicamentos no son eliminados por } \\
\text { HD. Se puede administrar en cualquier momento -antes o después- de la HD (39) } \\
\text { DP: } 250 \text { mg cada } 12 \text { horas (no requiere ajuste). La eliminación por DP es menor } \\
\text { que la observada con la HD convencional. Por la naturaleza continua de la DP, la } \\
\text { eliminación semanal acumulada es similar a la observada con HD intermitente (26) }\end{array}$ \\
\hline \multirow[t]{2}{*}{ Sofosbuvir } & \multirow[t]{2}{*}{$\begin{array}{l}1 \mathrm{a}, 1 \mathrm{~b} \\
2,3,4\end{array}$} & $\geq 30 \mathrm{~mL} / \mathrm{min}$ & No es necesario ajustar la dosis. & $\begin{array}{l}\text { No es necesario ajustar } \\
\text { la dosis. }\end{array}$ & $400 \mathrm{mg}$ cada 24 horas (no requiere ajuste) (35) \\
\hline & & $\begin{array}{l}<30 \mathrm{~mL} / \\
\text { min y ERCT } \\
\text { incluida HD }\end{array}$ & $\begin{array}{l}\text { No se proporcionan ajustes de dosis } \\
\text { en el etiquetado del fabricante (no } \\
\text { ha sido estudiado). Los metabolitos } \\
\text { predominantes se acumulan en } \\
\text { función renal deteriorada. }\end{array}$ & Sin datos & $\begin{array}{l}15-29 \mathrm{~mL} / \mathrm{min} / 1,73 \mathrm{~m}^{2}: 400 \mathrm{mg} \text { cada } 24 \text { horas (no requiere ajuste) }(27,33,35,40) \\
<15 \mathrm{~mL} / \mathrm{min} / 1,73 \mathrm{~m}^{2}: 400 \mathrm{mg} \text { cada } 24 \text { horas (no requiere ajuste) }(9,27,33,35,40) \\
\text { HD: } 400 \mathrm{mg} \text { cada } 24 \text { horas (no requiere ajuste) }(9,27,33,35,36) \\
\text { DP: } 400 \mathrm{mg} \text { cada } 24 \text { horas (no requiere ajuste) }(9,36) .\end{array}$ \\
\hline \multirow[t]{2}{*}{ Simeprevir } & \multirow[t]{2}{*}{1} & $>30 \mathrm{~mL} / \mathrm{min}$ & No es necesario ajustar la dosis. & $\begin{array}{l}\text { No es necesario ajustar } \\
\text { la dosis. }\end{array}$ & Sin datos \\
\hline & & $\begin{array}{l}\leq 30 \mathrm{~mL} / \\
\min , \mathrm{ERCT} \\
\text { incluida HD }\end{array}$ & $\begin{array}{l}\text { No se proporcionan ajustes de dosis } \\
\text { en el etiquetado del fabricante (no } \\
\text { ha sido estudiado). Es poco probable } \\
\text { que la diálisis resulte en la eliminación } \\
\text { significativa de simeprevir. }\end{array}$ & $\begin{array}{l}\text { No se ha establecido la } \\
\text { seguridad y eficacia de } \\
\text { simeprevir en pacientes } \\
\text { con infección por VHC e } \\
\text { insuficiencia renal grave. }\end{array}$ & $\begin{array}{l}15-29 \mathrm{~mL} / \mathrm{min} / 1,73 \mathrm{~m}^{2}: 150 \mathrm{mg} \text { cada } 24 \text { horas (no requiere ajuste) }(27,33) \\
<15 \mathrm{~mL} / \mathrm{min} / 1,73 \mathrm{~m}^{2}: 150 \mathrm{mg} \text { cada } 24 \text { horas (no requiere ajuste) }(27,36) \\
\text { HD: } 150 \mathrm{mg} \text { cada } 24 \text { horas (no requiere ajuste) }(27,33,36) \text {. No hay información } \\
\text { sobre su eliminación por HD. Se administró en cualquier momento -antes o después- } \\
\text { de la HD (27) } \\
\text { DP: } 150 \mathrm{mg} \text { cada } 24 \text { horas (no requiere ajuste) (36). No hay información sobre su } \\
\text { eliminación por DP. }\end{array}$ \\
\hline
\end{tabular}


Tabla 2. Recomendaciones de ajuste de dosis de medicamentos para pacientes con HC y ERC. Continuación

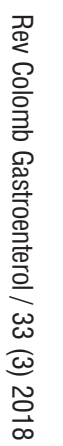

\begin{tabular}{|c|c|c|c|c|c|}
\hline \multirow[t]{2}{*}{ Medicamento } & \multirow[t]{2}{*}{ GNT } & \multirow[t]{2}{*}{ TFG } & \multicolumn{3}{|r|}{ Recomendaciones } \\
\hline & & & Uptodate (31) & Micromedex (32) & Presente revisión \\
\hline \multirow[t]{3}{*}{$\begin{array}{l}\text { Ledipasvir/ } \\
\text { sofosbuvir }\end{array}$} & \multirow[t]{3}{*}{$\begin{array}{l}1,4 \\
5,6\end{array}$} & $\geq 30 \mathrm{~mL} / \mathrm{min}$ & No es necesario ajustar la dosis. & $\begin{array}{l}\text { No es necesario ajustar } \\
\text { la dosis. }\end{array}$ & \multirow[t]{3}{*}{ No se encontró información sobre ledipasvir. Ver información de sofosbuvir. } \\
\hline & & $<30 \mathrm{~mL} / \mathrm{min}$ & $\begin{array}{l}\text { No se proporcionan ajustes de dosis } \\
\text { en el etiquetado del fabricante. Sin } \\
\text { embargo, el sofosbuvir y el metabolito } \\
\text { se acumulan en pacientes con } \\
\text { insuficiencia renal severa. }\end{array}$ & $\begin{array}{l}\text { No se ha establecido la } \\
\text { seguridad y la eficacia. }\end{array}$ & \\
\hline & & $\begin{array}{l}\text { ERCT } \\
\text { incluida HD } \\
\text { intermitente }\end{array}$ & $\begin{array}{l}\text { No hay ajustes de dosis } \\
\text { proporcionados en el etiquetado del } \\
\text { fabricante. Sin embargo, el sofosbuvir } \\
\text { y el metabolito se acumulan en } \\
\text { pacientes con insuficiencia renal } \\
\text { severa. En una sesión de diálisis de } 4 \\
\text { horas, se eliminó el } 18 \% \text { de la dosis de } \\
\text { sofosbuvir. }\end{array}$ & Sin datos & \\
\hline Daclatasvir & $\begin{array}{l}1,3 \text { off- } \\
\text { label: } 2\end{array}$ & $\begin{array}{l}\text { No } \\
\text { especificada }\end{array}$ & No es necesario ajustar la dosis. & $\begin{array}{l}\text { No es necesario ajustar } \\
\text { la dosis. }\end{array}$ & HD: 60 mg cada 24 horas (no requiere ajuste) $(13,16)$. \\
\hline \multirow[t]{3}{*}{ Asunaprevir } & \multirow[t]{3}{*}{1,4} & $\geq 30 \mathrm{~mL} / \mathrm{min}$ & No es necesario ajustar la dosis. & Sin datos & Sin datos \\
\hline & & $<30 \mathrm{~mL} / \mathrm{min}$ & $100 \mathrm{mg}$ cada 24 horas & Sin datos & Sin datos \\
\hline & & $\mathrm{HD}$ & $\begin{array}{l}100 \mathrm{mg} \text { cada } 12 \text { horas (es removido } \\
\text { por la HD). }\end{array}$ & Sin datos & HD: 100 mg cada 12 horas (no requiere ajuste) $(13,16)$. \\
\hline \multirow[t]{3}{*}{ RBV } & \multirow[t]{3}{*}{ NR } & $\geq 50 \mathrm{~mL} / \mathrm{min}$ & $\begin{array}{l}\text { No es necesario ajustar la dosis } \\
\text { (Rebetol cápsulas/solución, } \\
\text { Ribasphere cápsulas y tabletas, } \\
\text { Copegus y Moderiba tableta). }\end{array}$ & $\begin{array}{l}\text { No es necesario ajustar } \\
\text { la dosis. }\end{array}$ & Sin datos \\
\hline & & $<50 \mathrm{~mL} / \mathrm{min}$ & $\begin{array}{l}\text { Uso contraindicado. Niños con } \mathrm{Cr}>2 \\
\text { mg/dL: descontinuar permanentemente } \\
\text { el tratamiento (Rebetol cápsulas/ } \\
\text { solución, Ribasphere cápsulas). } \\
\text { Uso no recomendado (Ribasphere } \\
\text { tabletas). }\end{array}$ & $\begin{array}{l}\text { Uso no recomendado. } \\
\text { Niños: } \mathrm{Cr}>2 \mathrm{mg} / \\
\mathrm{dL} \text { : descontinuar el } \\
\text { tratamiento (Rebetol). }\end{array}$ & Ver recomendaciones para TFG $30-50 \mathrm{~mL} / \mathrm{min}$ y $<30 \mathrm{~mL} / \mathrm{min}$, ERCT incluida HD. \\
\hline & & $\begin{array}{l}30 \text { a } 50 \mathrm{~mL} / \\
\min \end{array}$ & $\begin{array}{l}\text { Alternar } 200 \text { mg y } 400 \text { mg cada otro } \\
\text { día (Copegus y Moderiba tableta). }\end{array}$ & $\begin{array}{l}\text { Alternar } 200 \mathrm{mg} \text { y } 400 \mathrm{mg} \\
\text { cada otro día (Copegus). }\end{array}$ & 200 y $400 \mathrm{mg}$ alternados diariamente (41). \\
\hline
\end{tabular}


Tabla 2. Recomendaciones de ajuste de dosis de medicamentos para pacientes con HC y ERC. Continuación

\begin{tabular}{|c|c|c|c|c|c|}
\hline \multirow[t]{2}{*}{ Medicamento } & \multirow[t]{2}{*}{ GNT } & \multirow[t]{2}{*}{ TFG } & \multicolumn{3}{|r|}{ Recomendaciones } \\
\hline & & & Uptodate (31) & Micromedex (32) & Presente revisión \\
\hline RBV & NR & $\begin{array}{l}<30 \mathrm{~mL} / \\
\text { min, ERCT } \\
\text { incluida HD }\end{array}$ & $\begin{array}{l}200 \text { mg una vez al día (Copegus y } \\
\text { Moderiba tableta) }\end{array}$ & $\begin{array}{l}200 \text { mg una vez al día } \\
\text { (Copegus) }\end{array}$ & $\begin{array}{l}15-29 \mathrm{~mL} / \mathrm{min} / 1.73 \mathrm{~m}^{2}: 200 \mathrm{mg} \text { cada } 24 \text { horas (33,39-41) } \\
<15 \mathrm{~mL} / \mathrm{min} / 1,73 \mathrm{~m} \text { : } 200 \mathrm{mg} \text { cada } 24 \text { horas }(33,39-41) \\
\text { HD: } 200 \mathrm{mg} \text { cada } 24 \text { horas }(39,41) ; 200-400 \mathrm{mg} \text { semanales (34); } 200 \mathrm{mg} \text { cada } 48 \\
\text { horas en días de no diálisis (28). } \\
\text { Eliminación mínima por HD. Se administró en cualquier momento -antes o después- } \\
\text { de la HD (39). Debido al gran volumen de distribución, RBV no se elimina de manera } \\
\text { eficiente por HD porque solo una pequeña parte de la cantidad total de fármaco en el } \\
\text { cuerpo está disponible para ser eliminada por HD (41). } \\
\text { DP: } 200 \text { mg cada } 24 \text { horas. La eliminación por DP es menor que la observada con } \\
\text { la HD convencional. Por la naturaleza continua de la DP, la eliminación semanal } \\
\text { acumulada es similar a la observada con HD intermitente (34). }\end{array}$ \\
\hline \multirow[t]{2}{*}{ PEG-IFN a2a } & \multirow{2}{*}{$\begin{array}{l}2,3,4 \\
5,6\end{array}$} & $\geq 30 \mathrm{~mL} / \mathrm{min}$ & No requiere ajuste de dosis. & No requiere ajuste. & $80-180 \mu \mathrm{g}$ cada semana (42). \\
\hline & & $\begin{array}{l}<30 \mathrm{~mL} / \\
\text { min, ERCT } \\
\text { incluida HD }\end{array}$ & $\begin{array}{l}135 \mu \mathrm{g} \text { una vez a la semana; } \\
\text { monitorizar por toxicidad. } \\
\text { Si se presentan reacciones adversas } \\
\text { severas o anormalidades de } \\
\text { laboratorio, puede reducir la dosis a } \\
90 \mu \mathrm{g} \text { una vez por semana hasta que } \\
\text { las reacciones adversas se resuelvan; } \\
\text { si la intolerancia persiste después del } \\
\text { ajuste de la dosis, descontinuar. }\end{array}$ & $\begin{array}{l}\text { Reducir a } 135 \mu \mathrm{g} / \\
\text { semana; si se desarrollan } \\
\text { reacciones adversas } \\
\text { severas, reducir a } 90 \mu \mathrm{g} / \\
\text { semana. Si la intolerancia } \\
\text { persiste, descontinuar la } \\
\text { terapia. En niños no ha } \\
\text { sido evaluado. }\end{array}$ & HD: $90-135 \mu \mathrm{g}$ una vez a la semana $(34,43) ; 135 \mu \mathrm{g}$ cada 14 días (28). \\
\hline \multirow[t]{4}{*}{ PEG-IFN a2b } & \multirow[t]{4}{*}{ NR } & $<50 \mathrm{~mL} / \mathrm{min}$ & $\begin{array}{l}\text { No se recomienda la combinación con } \\
\text { RBV. } \\
\text { Niños: } \mathrm{Cr}>2 \mathrm{mg} / \mathrm{dL} \text { : descontinuar } \\
\text { tratamiento. }\end{array}$ & $\begin{array}{l}\text { No se recomienda la } \\
\text { combinación con RBV. }\end{array}$ & \multirow[t]{4}{*}{ Sin datos } \\
\hline & & $\begin{array}{l}30-50 \mathrm{~mL} / \\
\min \end{array}$ & $\begin{array}{l}\text { Reducir dosis en } 25 \% \text { (en } \\
\text { monoterapia)*. }\end{array}$ & Reducir dosis en $25 \%$. & \\
\hline & & $\begin{array}{l}10-29 \mathrm{~mL} / \\
\min \end{array}$ & $\begin{array}{l}\text { Reducir dosis en } 50 \% \text { (en } \\
\text { monoterapia)*. }\end{array}$ & Reducir dosis en $50 \%$. & \\
\hline & & $\mathrm{HD}$ & $\begin{array}{l}\text { Reducir dosis en } 50 \% \text { (en } \\
\text { monoterapia). }\end{array}$ & Reducir dosis en $50 \%$. & \\
\hline
\end{tabular}

*Suspender el uso si la función renal disminuye durante el tratamiento. Cr: creatinina; DP: diálisis peritoneal; ERCT: enfermedad renal crónica terminal; GNT: genotipo; HD: hemodiálisis; NR: no reporta. 
Tabla 3. Revisión de la seguridad y la eficacia de los medicamentos para la HC en pacientes de edad avanzada con ERC: resultados de la revisión

\begin{tabular}{|c|c|c|c|c|c|c|c|c|c|}
\hline Medicamento & GNT & TFG & $\begin{array}{l}\text { Estadio } \\
\text { ERC }\end{array}$ & Dosis utilizada & Eficacia & EAM & Tipo de estudio & $\begin{array}{l}\text { Edad media } \pm \\
\text { DE (rango) }\end{array}$ & Ref. \\
\hline \multirow[t]{2}{*}{$\begin{array}{l}\text { Elbasvir/ } \\
\text { grazoprevir }\end{array}$} & 1 & $15-29 \mathrm{~mL} / \mathrm{min}$ & 4 & $\begin{array}{l}50 / 100 \mathrm{mg} \text { cada } 24 \text { horas (no } \\
\text { requiere ajuste) }\end{array}$ & $\begin{array}{l}\text { RVS12*: 100\% (22/22) } \\
{ }^{*} \text { ARN-VHC <15 UI/mL }\end{array}$ & \multirow{2}{*}{$\begin{array}{l}\text { Cefalea, náuseas, fatiga, } \\
\text { eventos cardíacos (paro } \\
\text { cardíaco, infarto de miocardio, } \\
\text { cardiomiopatía), insuficiencia } \\
\text { cardíaca congestiva, neumonía, } \\
\text { hipertensión }\end{array}$} & \multirow{2}{*}{$\begin{array}{l}\text { C-SURFER: ensayo } \\
\text { clínico aleatorizado } \\
\text { de seguridad/estudio } \\
\text { observacional de } \\
\text { eficacia }\end{array}$} & \multirow{2}{*}{$\begin{array}{l}\text { Población } \\
\text { farmacocinética: } \\
58,2 \pm 16,8 \\
\text { (NR) } \\
\text { Grupo de } \\
\text { tratamiento: } \\
56,5 \pm 9,1 \text { (NR) }\end{array}$} & \multirow[t]{2}{*}{ (29) } \\
\hline & & $<15 \mathrm{~mL} / \mathrm{min}$ & 5 & $\begin{array}{l}50 / 100 \text { mg cada } 24 \text { horas (no } \\
\text { requiere ajuste) }\end{array}$ & $\begin{array}{l}\text { RVS12*: 98,9\% (93/94) } \\
{ }^{*} A R N-V H C<15 \mathrm{IU} / \mathrm{mL}\end{array}$ & & & & \\
\hline \multirow{5}{*}{$\begin{array}{l}\text { Ombitasvir/ } \\
\text { paritaprevir/ } \\
\text { ritonavir }\end{array}$} & 1 & $30-89 \mathrm{~mL} / \mathrm{min}$ & 2 у 3 & $\begin{array}{l}25 / 150 / 100 \mathrm{mg} \text { cada } 24 \text { horas (no } \\
\text { requiere ajuste) }\end{array}$ & No estudiada & Sin datos & $\begin{array}{l}\text { Estudio de } \\
\text { farmacocinética }\end{array}$ & $54(18-71)$ & (37) \\
\hline & $1 b$ & $\begin{array}{l}40,0-164,0 \\
\mathrm{~mL} / \mathrm{min}\end{array}$ & 1,2 y 3 & $\begin{array}{l}\text { 25/150/100 mg cada } 24 \text { horas (no } \\
\text { requiere ajuste) }\end{array}$ & No estudiada & Sin datos & $\begin{array}{l}\text { Estudio de } \\
\text { farmacocinética }\end{array}$ & $61,2(29,0-76,0)$ & (38) \\
\hline & $\begin{array}{l}1 \mathrm{a}, \\
1 \mathrm{~b}\end{array}$ & $15-30 \mathrm{~mL} / \mathrm{min}$ & 4 & $\begin{array}{l}25 / 150 / 100 \text { mg cada } 24 \text { horas (no } \\
\text { requiere ajuste) }\end{array}$ & $\begin{array}{l}\text { RVS12*: } 100 \%(6 / 6) \\
{ }^{*} A R N-V H C<25 \mathrm{UI} / \mathrm{mL}\end{array}$ & \multirow{2}{*}{$\begin{array}{l}\text { Fatiga, diarrea y edema } \\
\text { periférico. } \\
\text { En concomitancia con RBV: } \\
\text { anemia, náuseas y cefalea }\end{array}$} & \multirow[t]{2}{*}{$\begin{array}{l}\text { Ensayo clínico } \\
\text { aleatorizado }\end{array}$} & \multirow[t]{2}{*}{$60(49-69)$} & \multirow[t]{2}{*}{ (39) } \\
\hline & & $\begin{array}{l}<15 \mathrm{~mL} / \mathrm{min} 0 \\
\text { en } \mathrm{HD}\end{array}$ & 5 & $\begin{array}{l}\text { 25/150/100 mg cada } 24 \text { horas } \\
\text { (no requiere ajuste. Se administró } \\
\text { en cualquier momento -antes } \\
\text { o después- de la HD). Datos } \\
\text { limitados; sin embargo, sugieren } \\
\text { que estos medicamentos no son } \\
\text { extraídos por HD. }\end{array}$ & $\begin{array}{l}\text { RVS12*: 85,7\% (12/14) } \\
{ }^{*} \text { ARN-VHC <25 UI/mL }\end{array}$ & & & & \\
\hline & $1 \mathrm{a}$ & DP & 5 & $\begin{array}{l}\text { 12,5/75/50 mg cada } 24 \text { horas. } \\
\text { La eliminación por DP es menor } \\
\text { que la observada con la HD } \\
\text { convencional. Por la naturaleza } \\
\text { continua de la DP, la eliminación } \\
\text { semanal acumulada es similar a la } \\
\text { observada con HD intermitente. }\end{array}$ & RVS12: 100\% (1/1) & $\begin{array}{l}\text { Fatiga, disminución del apetito, } \\
\text { disminución de niveles de } \\
\text { hemoglobina }\end{array}$ & Reporte de caso & 73 & (26) \\
\hline \multirow[t]{3}{*}{ Dasabuvir } & 1 & $30-89 \mathrm{~mL} / \mathrm{min}$ & 2 y 3 & $\begin{array}{l}250 \mathrm{mg} \text { cada } 12 \text { horas (no requiere } \\
\text { ajuste) }\end{array}$ & No estudiada & Sin datos & $\begin{array}{l}\text { Estudio de } \\
\text { farmacocinética }\end{array}$ & $54(18-71)$ & (37) \\
\hline & $\begin{array}{l}1 \mathrm{a} y \\
1 \mathrm{~b}\end{array}$ & $15-30 \mathrm{~mL} / \mathrm{min}$ & 4 & $\begin{array}{l}250 \mathrm{mg} \text { cada } 12 \text { horas (no requiere } \\
\text { ajuste) }\end{array}$ & $\begin{array}{l}\text { RVS12*: } 100 \%(6 / 6) \\
{ }^{*} \text { ARN-VHC <25 UI/mL }\end{array}$ & \multirow{2}{*}{$\begin{array}{l}\text { Fatiga, diarrea y edema } \\
\text { periférico. } \\
\text { En concomitancia con RBV: } \\
\text { anemia, náuseas y cefalea. }\end{array}$} & \multirow[t]{2}{*}{$\begin{array}{l}\text { Ensayo clínico } \\
\text { aleatorizado }\end{array}$} & \multirow[t]{2}{*}{$60(49-69)$} & \multirow[t]{2}{*}{ (39) } \\
\hline & & $\begin{array}{l}<15 \mathrm{~mL} / \mathrm{min} 0 \\
\text { en } \mathrm{HD}\end{array}$ & 5 & $\begin{array}{l}250 \text { mg cada } 12 \text { horas (no requiere } \\
\text { ajuste, se administró en cualquier } \\
\text { momento -antes o después- de la } \\
\text { HD). Datos limitados; sin embargo, } \\
\text { sugieren que estos medicamentos } \\
\text { no son extraídos por HD. }\end{array}$ & $\begin{array}{l}\text { RVS12*: 85,7\% (12/14) } \\
\text { *ARN-VHC <25 UI/mL }\end{array}$ & & & & \\
\hline
\end{tabular}


Tabla 3. Revisión de la seguridad y la eficacia de los medicamentos para la HC en pacientes de edad avanzada con ERC: resultados de la revisión. Continuación

\begin{tabular}{|c|c|c|c|c|c|c|c|c|c|}
\hline Medicamento & GNT & TFG & $\begin{array}{c}\text { Estadio } \\
\text { ERC }\end{array}$ & Dosis utilizada & Eficacia & EAM & Tipo de estudio & $\begin{array}{c}\text { Edad media } \pm \\
\text { DE (rango) }\end{array}$ & Ref. \\
\hline Dasabuvir & $1 \mathrm{a}$ & $\mathrm{DP}$ & 5 & $\begin{array}{l}250 \text { mg cada } 12 \text { horas (no requiere } \\
\text { ajuste). La eliminación por DP es } \\
\text { menor que la observada con la HD } \\
\text { convencional. Por la naturaleza } \\
\text { continua de la DP, la eliminación } \\
\text { semanal acumulada es similar a la } \\
\text { observada con HD intermitente. }\end{array}$ & RVS12: 100\% (1/1) & $\begin{array}{l}\text { Fatiga, disminución del apetito, } \\
\text { disminución de niveles de } \\
\text { hemoglobina }\end{array}$ & Reporte de caso & 73 & (26) \\
\hline \multirow[t]{7}{*}{ Sofosbuvir } & \multirow[t]{2}{*}{$\begin{array}{l}1 \\
3,4\end{array}$} & $\begin{array}{l}\mathrm{HD}(8 \\
\text { pacientes) }\end{array}$ & \multirow[t]{2}{*}{5} & $\begin{array}{l}400 \text { mg cada } 24 \text { horas ( } 1 \text { tuvo } \\
\text { ajuste de dosis a } 400 \text { mg cada } 48 \\
\text { horas y se cambió simeprevir a } \\
\text { daclatasvir) }\end{array}$ & \multirow[t]{2}{*}{$\begin{array}{l}\text { RVS12*: } 90 \%(9 / 10) \\
{ }^{*} \mathrm{ARN}-\mathrm{VHC}<12-15 \\
\text { IU } / \mathrm{mL}\end{array}$} & $\begin{array}{l}\text { Trombocitopenia, neumonía, } \\
\text { fatiga, cefalea, náusea, mialgia/ } \\
\text { artralgia }\end{array}$ & \multirow[t]{2}{*}{ Estudio de cohortes } & \multirow[t]{2}{*}{$\begin{array}{l}50,6 \pm 10,9 \\
(31-69)\end{array}$} & \multirow[t]{2}{*}{ (9) } \\
\hline & & $\begin{array}{l}\mathrm{DP}(2 \\
\text { pacientes })\end{array}$ & & 400 mg cada 24 horas & & $\begin{array}{l}\text { Anemia hemolítica, peritonitis, } \\
\text { neumonía, fatiga, cefalea, } \\
\text { náusea, mialgia/artralgia }\end{array}$ & & & \\
\hline & \multirow[t]{3}{*}{1} & $\begin{array}{l}\mathrm{HD}(11 \\
\text { pacientes) }\end{array}$ & \multirow[t]{3}{*}{5} & $\begin{array}{l}200 \text { mg cada } 24 \text { horas ( } 1 \text { h antes } \\
\text { de la diálisis) } \\
\text { Eliminado en diálisis } \\
\text { Dosis de } 400 \text { mg: administrado } 1 \mathrm{~h} \\
\text { pre- HD: ABC de sofosbuvir: } 28 \% \text {, } \\
\text { GS-331007: } 1280 \% \text {; administrado } \\
1 \text { h post-HD: ABC sofosbuvir: } 60 \% \text {, } \\
\text { GS-331007: } 2070 \%\end{array}$ & \multirow[t]{2}{*}{$\begin{array}{l}\text { RVS12*: 83,3\% (10/12) } \\
{ }^{*} \text { ARN-VHC <15 IU/mL }\end{array}$} & \multirow[t]{3}{*}{$\begin{array}{l}\text { Fatiga, erupción/picazón, } \\
\text { anemia, diarrea y pérdida de } \\
\text { apetito }\end{array}$} & \multirow[t]{3}{*}{ Estudio abierto } & \multirow[t]{3}{*}{$\begin{array}{l}59,7 \pm 7,2 \\
(39-77)\end{array}$} & \multirow[t]{3}{*}{$(36$} \\
\hline & & $\begin{array}{l}\mathrm{DP}(1 \\
\text { paciente) }\end{array}$ & & 400 mg cada 48 horas & & & & & \\
\hline & & 8-15 mL/min & & & $\begin{array}{l}\text { RVS12*: } 100 \%(3 / 3) \\
{ }^{*} A R N-V H C<15 \mathrm{IU} / \mathrm{mL}\end{array}$ & & & & \\
\hline & \multirow[t]{2}{*}{1} & $<30 \mathrm{~mL} / \mathrm{min}$ & 4 y 5 & 400 mg cada 24 horas & RVS12: 50\% (2/4) & $\begin{array}{l}\text { Anemia (en } 2 \text { pacientes con } \\
\text { RBV), leucopenia (en } 1 \text { paciente } \\
\text { con PEG-IFN), Enfermedad } \\
\text { glomerular del complejo } \\
\text { inmune similar al lupus con } \\
\text { nefritis tubulointersticial } \\
\text { (concomitantemente RBV, se } \\
\text { tenían títulos altos antes del } \\
\text { inicio de la terapia) }\end{array}$ & \multirow[t]{2}{*}{ Series de casos } & \multirow[t]{2}{*}{$60 \pm 14$} & \multirow[t]{2}{*}{ (33) } \\
\hline & & $\mathrm{HD}$ & 5 & 400 mg cada 24 horas & RVS12: 100\% (2/2) & $\begin{array}{l}\text { Anemia (en } 1 \text { paciente en } \\
\text { tratamiento concomitante con } \\
\text { RBV) }\end{array}$ & & & \\
\hline
\end{tabular}


Tabla 3. Revisión de la seguridad y la eficacia de los medicamentos para la HC en pacientes de edad avanzada con ERC: resultados de la revisión. Continuación




Tabla 3. Revisión de la seguridad y la eficacia de los medicamentos para la HC en pacientes de edad avanzada con ERC: resultados de la revisión. Continuación

\begin{tabular}{|c|c|c|c|c|c|c|c|c|c|}
\hline Medicamento & GNT & TFG & $\begin{array}{l}\text { Estadio } \\
\text { ERC }\end{array}$ & Dosis utilizada & Eficacia & EAM & Tipo de estudio & $\begin{array}{l}\text { Edad media } \pm \\
\text { DE (rango) }\end{array}$ & Ref. \\
\hline \multirow[t]{7}{*}{ RBV } & \multirow[t]{2}{*}{1} & $<30 \mathrm{~mL} / \mathrm{min}$ & 4 y 5 & $\begin{array}{l}200 \mathrm{mg} \text { cada } 24 \text { horas y } 400 \mathrm{mg} \\
\text { cada } 12 \text { horas }\end{array}$ & RVS12: $50 \%(1 / 2)$ & $\begin{array}{l}\text { Anemia, leucopenia (en } 1 \\
\text { paciente con PEG-IFN), } \\
\text { enfermedad glomerular del } \\
\text { complejo inmune similar al lupus } \\
\text { con nefritis tubulointersticial } \\
\text { (concomitantemente sofosbuvir, } \\
\text { se tenían títulos altos antes del } \\
\text { inicio de la terapia.) }\end{array}$ & \multirow[t]{2}{*}{ Series de casos } & \multirow[t]{2}{*}{$60 \pm 14$} & \multirow[t]{2}{*}{ (33) } \\
\hline & & $\mathrm{HD}$ & 5 & 200 mg cada 12 horas & RVS12: 100\% (1/1) & Anemia & & & \\
\hline & \multirow[t]{3}{*}{$1-3$} & $30-50 \mathrm{~mL} / \mathrm{min}$ & 3 & $\begin{array}{l}600 \mathrm{mg} \text { (ajustada luego a } 200 \text { y } \\
400 \mathrm{mg} \text { alternados diariamente) }\end{array}$ & No estudiada & \multirow{3}{*}{$\begin{array}{l}\text { Anemia, cambios en el } \\
\text { estado mental, fatiga, dolor } \\
\text { de cabeza, náuseas, pirexia, } \\
\text { diarrea, escalofríos y artralgia } \\
\text { (concomitantemente con } \\
\text { PEG-IFN a2a). Los ajustes de } \\
\text { dosis de RBV se debieron a la } \\
\text { disminución de la hemoglobina } \\
\leq 10 \text { g/dL o una disminución del } \\
\text { valor inicial en la concentración } \\
\text { de hemoglobina de } \geq 3 \text { g/dL, } \\
\text { disminución en el recuento de } \\
\text { glóbulos blancos y plaquetas. }\end{array}$} & \multirow{3}{*}{$\begin{array}{l}\text { Estudio clínico } \\
\text { aleatorizado no } \\
\text { controlado/estudio de } \\
\text { farmacocinética }\end{array}$} & \multirow[t]{3}{*}{$23-65$} & \multirow[t]{3}{*}{ (41) } \\
\hline & & $<30 \mathrm{~mL} / \mathrm{min}$ & 4 y 5 & 200 mg cada 24 horas & No estudiada & & & & \\
\hline & & $\mathrm{HD}$ & 5 & $\begin{array}{l}200 \text { mg cada } 24 \text { horas. Debido } \\
\text { al gran volumen de distribución, } \\
\text { RBV no se elimina de manera } \\
\text { eficiente por HD porque solo una } \\
\text { pequeña parte de la cantidad } \\
\text { total de fármaco en el cuerpo está } \\
\text { disponible para ser eliminada por } \\
\text { HD. }\end{array}$ & No estudiada & & & & \\
\hline & $\begin{array}{l}\text { Sin } \\
\text { datos }\end{array}$ & DP & 5 & $\begin{array}{l}200 \text { mg cada } 24 \text { horas (ajustada } \\
\text { posteriormente a } 200 \text { mg cada } 48 \\
\text { horas y descontinuada) } \\
\text { La eliminación por DP es menor } \\
\text { que la observada con la HD } \\
\text { convencional. Por la naturaleza } \\
\text { continua de la DP, la eliminación } \\
\text { semanal acumulada es similar a la } \\
\text { observada con HD intermitente. }\end{array}$ & RVS12: 100\% (1/1) & $\begin{array}{l}\text { Fatiga, disminución del apetito, } \\
\text { disminución de niveles de } \\
\text { hemoglobina }\end{array}$ & Reporte de caso & 73 & $(26)$ \\
\hline & $1 b$ & $\mathrm{HD}$ & 5 & $200-400 \mathrm{mg}$ semanales & $\begin{array}{l}\text { RVS24*: 73,9\% (17/23 } \\
\text { PEG-IFNa2a y RBV) } \\
{ }^{*} \text { Negatividad (<15 UI/ } \\
\mathrm{mL})\end{array}$ & $\begin{array}{l}\text { Rechazo de aloinjerto renal no } \\
\text { funcional, trombocitopenia con } \\
\text { complicaciones hemorrágicas, } \\
\text { neumonía, anemia, } \\
\text { pancitopenia (concomitante con } \\
\text { PEG-IFN) }\end{array}$ & $\begin{array}{l}\text { Estudio de casos y } \\
\text { controles }\end{array}$ & $52(25-69)$ & (34) \\
\hline
\end{tabular}


Tabla 3. Revisión de la seguridad y la eficacia de los medicamentos para la HC en pacientes de edad avanzada con ERC: resultados de la revisión. Continuación

\begin{tabular}{|c|c|c|c|c|c|c|c|c|c|}
\hline Medicamento & GNT & TFG & $\begin{array}{c}\text { Estadio } \\
\text { ERC }\end{array}$ & Dosis utilizada & Eficacia & EAM & Tipo de estudio & $\begin{array}{c}\text { Edad media } \pm \\
\text { DE (rango) }\end{array}$ & Ref. \\
\hline \multirow[t]{4}{*}{ RBV } & \multirow[t]{2}{*}{$1 \mathrm{a}$} & $15-30 \mathrm{~mL} / \mathrm{min}$ & 4 & $200 \mathrm{mg}$ cada 24 horas & \multirow{2}{*}{$\begin{array}{l}\text { RVS12*: 84,6\% (11/13) } \\
{ }^{*} \text { ARN-VHC <25 Ul/mL }\end{array}$} & \multirow{2}{*}{$\begin{array}{l}\text { Anemia, fatiga, diarrea, } \\
\text { náuseas, cefalea y edema } \\
\text { periférico }\end{array}$} & \multirow{2}{*}{$\begin{array}{l}\text { Ensayo clínico } \\
\text { aleatorizado }\end{array}$} & \multirow[t]{2}{*}{$60(49-69)$} & \multirow[t]{2}{*}{ (39) } \\
\hline & & $\begin{array}{l}<15 \mathrm{~mL} / \mathrm{min} 0 \\
\text { en } \mathrm{HD}\end{array}$ & 5 & $\begin{array}{l}200 \text { mg cada } 24 \text { horas (se } \\
\text { administró en cualquier momento } \\
\text {-antes o después- de la HD). } \\
\text { Eliminación mínima por HD. }\end{array}$ & & & & & \\
\hline & 1 & $\begin{array}{l}<30 \mathrm{~mL} / \mathrm{min} \\
(\sin \mathrm{HD})\end{array}$ & 4 y 5 & $200 \mathrm{mg}$ cada 24 horas & $\begin{array}{l}\text { RVS12*: } 60 \%(6 / 10) \\
{ }^{*} \text { ARN-VHC <15 IU/mL }\end{array}$ & $\begin{array}{l}\text { Fatiga, alteración renal, } \\
\text { neumonía, anemia, } \\
\text { hematemesis }\end{array}$ & Estudio abierto & $58(45-75)$ & $(40)$ \\
\hline & 2 & $\mathrm{HD}$ & 5 & $\begin{array}{l}\text { Inicial: } 200 \text { mg cada } 24 \text { horas, } \\
\text { posteriormente ajustada a } 200 \\
\text { mg cada } 48 \text { horas en días de no } \\
\text { diálisis }\end{array}$ & RVS24: 100\% (1/1) & Disminución de hemoglobina & Reporte de caso & 67 & $(28)$ \\
\hline \multirow[t]{4}{*}{ PEG-IFN a2a } & $\begin{array}{l}1 \mathrm{a} \\
1 \mathrm{~b}, 4\end{array}$ & $\begin{array}{l}38-132 \mathrm{~mL} / \\
\min \end{array}$ & 1,2 y 3 & $\begin{array}{l}135 \mu \mathrm{g} \text { cada semana (8 pacientes); } \\
80 \mu \mathrm{g} \text { cada semana ( } 3 \text { pacientes) y } \\
180 \mu \mathrm{g} \text { cada semana ( } 1 \text { paciente) }\end{array}$ & RVS24: 33,3\% (4/12) & $\begin{array}{l}\text { Leucopenia, astenia, anemia, } \\
\text { trombocitopenia, depresión, } \\
\text { hipotiroidismo, artralgia }\end{array}$ & $\begin{array}{l}\text { Estudio de casos y } \\
\text { controles }\end{array}$ & $59,7(35-74,9)$ & $(42)$ \\
\hline & $\begin{array}{l}1 b \\
2 a \\
2 b\end{array}$ & $\mathrm{HD}$ & 5 & $90-135 \mu \mathrm{g} 1$ vez a la semana & $\begin{array}{l}\text { RVS: } 33,3 \%(6 / 18 \\
\text { casos). } \\
\text { No definen RVS }\end{array}$ & $\begin{array}{l}\text { Epistaxis, anemia, neutropenia, } \\
\text { trombocitopenia, depresión, } \\
\text { neumonía intersticial }\end{array}$ & Estudio descriptivo & $\begin{array}{l}55,7 \pm 11,1 \\
(28-70)\end{array}$ & (43) \\
\hline & $1 b$ & $\mathrm{HD}$ & 5 & $\begin{array}{l}\text { 90-135 } \mu \mathrm{g} \text { una vez a la semana } \\
\text { (se inició con } 135 \mu \mathrm{g} / \mathrm{semana} \text { y } \\
\text { se redujo a } 90 \mu \mathrm{g} \text { por EAM. Se } \\
\text { administró después de la HD.) }\end{array}$ & $\begin{array}{l}\text { RVS24*: 50,0\% (8/16 } \\
\text { en monoterapia). } \\
\text { 73,9\% (17/23 PEG-IFN } \\
\text { a2a y RBV) } \\
\text { Total estudio: } 64,1 \% \\
\text { (25/39) } \\
\text { *Negatividad (<15 UI/ } \\
\text { mL) }\end{array}$ & $\begin{array}{l}\text { Rechazo de aloinjerto renal no } \\
\text { funcional, trombocitopenia con } \\
\text { complicaciones hemorrágicas, } \\
\text { neumonía, anemia, } \\
\text { pancitopenia (monoterapia y } \\
\text { combinado con RBV) }\end{array}$ & $\begin{array}{l}\text { Estudio de casos y } \\
\text { controles }\end{array}$ & $52(25-69)$ & $(34)$ \\
\hline & 2 & $\mathrm{HD}$ & 5 & $\begin{array}{l}\text { Inicio: } 135 \mu \mathrm{g} 1 \text { vez a la semana, } \\
\text { posteriormente se ajustó a } 135 \\
\mu g \text { cada } 14 \text { días por descenso de } \\
\text { plaquetas. }\end{array}$ & RVS24: 100\% (1/1) & Disminución de plaquetas & Reporte de caso & 67 & $(28)$ \\
\hline
\end{tabular}

ABC: área bajo la curva; ALT: alanina-aminotransferasa; ARN-VHC: (carga viral) ácido ribonucleico del virus de la hepatitis C; DP: diálisis peritoneal; HD: hemodiálisis; NR: no reporta; RVS: respuesta virológica sostenida. 
horas en pacientes con TFG $<15 \mathrm{~mL} / \mathrm{min} / 1,73 \mathrm{~m}^{2}$ y 200 mg al día en pacientes con HD. Solo 2 estudios reportaron el uso de sofosbuvir en DP: Beinhardt y colaboradores (9) utilizaron dosis plenas, mientras que Bhamidimarri y colaboradores (36) ajustaron la dosis a $400 \mathrm{mg}$ cada 48 horas.

Autores como Bunchorntavakul C y colaboradores (12) realizaron una revisión para evaluar el tratamiento del VHC en pacientes con TFG $<30 \mathrm{~mL} / \mathrm{min} / 1,73 \mathrm{~m}^{2}$, sometidos a TR o con ERC relacionada con el VHC. A partir de la información encontrada, elaboraron una figura con las estrategias para el manejo del VHC en pacientes con ERC y TR, con PEG-IFN, RBV, sofosbuvir, simeprevir, boceprevir y telaprevir, estos 2 últimos ya retirados del mercado. Igualmente, Sorbera y colaboradores (11) elaboraron una tabla con las recomendaciones de dosificación de sofosbuvir, simeprevir, ledipasvir, daclatasvir, ombitasvir/paritaprevir y dasabuvir en pacientes con alteración renal.

A diferencia de las revisiones anteriormente mencionadas, este trabajo presenta recomendaciones sobre 7 estrategias terapéuticas con $\mathrm{AAD}$ de segunda generación (elbasvir/grazoprevir, paritaprevir/ombitasvir/ritonavir, dasabuvir, sofosbuvir, simeprevir, daclatasvir y asunaprevir), PEG-IFN y RBV, y amplía la información sobre el uso de sofosbuvir en pacientes de edad avanzada, con TFG $<30$ $\mathrm{mL} / \mathrm{min}$ y en diálisis; mientras que, Bunchorntavakul y colaboradores (12) no confirman las dosis de daclatasvir, ombitasvir/paritaprevir, dasabuvir, ni elbasvir/grazoprevir, puesto que no estaban disponibles al momento de su revisión; y Sorbera y colaboradores (11) no ofrecieron datos sobre el uso de asunaprevir en ningún estadio de ERC ni presentaron información sobre elbasvir/grazoprevir. Adicionalmente, dichas revisiones no expresaron las edades de los pacientes incluidos en los estudios revisados, ni presentaron información sobre los EAM presentados, lo que impide conocer la utilización, dosificación y seguridad de los AAD en pacientes de edad avanzada con ERC.

\section{Tratamiento de la $\mathrm{HC}$ en pacientes de edad avanzada con ERC}

Se sugiere tratar a los pacientes de edad avanzada, con $\mathrm{HC}$ y ERC, con fármacos que preferiblemente no sean excretados por vía renal, para evitar su acumulación o la de sus metabolitos. Por una parte, elbasvir/grazoprevir, paritaprevir/ombitasvir/ritonavir, dasabuvir, daclatasvir, asunaprevir, ledipasvir y simeprevir se metabolizan principalmente por vía hepática $(16,26,44)$. Por otra parte, el sofosbuvir, piedra angular de varios esquemas, tiene excreción renal (a través del metabolito inactivo GS-331007) y puede limitar el uso de otros $\mathrm{AAD}$ con los que se usa concomitantemente, como ledipasvir, simeprevir y daclatasvir, en pacientes con ERCT (26).
Actualmente, el inserto del sofosbuvir no contiene recomendaciones de dosificación en pacientes con TFG $<30$ $\mathrm{mL} / \mathrm{min} / 1,73 \mathrm{~m}^{2}$ o ERCT, debido a que hay evidencia de exposiciones más altas (hasta 20 veces) del metabolito de sofosbuvir predominante, el GS331007 (45). Sin embargo, estudios incluidos en esta revisión han mostrado la utilización exitosa de dosis completas de sofosbuvir ( $400 \mathrm{mg}$ cada 24 horas) en estadios 4 y 5 , incluidos pacientes con $\mathrm{HD}$ y $\mathrm{DP}$, sin grandes implicaciones en la seguridad. Inclusive, algunos de los EAM reportados en pacientes que utilizaron sofosbuvir pudieron asociarse principalmente con el uso concomitante de PEG-IFN y/o RBV.

Se debe considerar que en pacientes con HD se presenta una eliminación considerable del sofosbuvir y su metabolito predominante (45); sin embargo, los autores que reportaron el uso de dosis completas de este medicamento en dicha población no brindan información sobre el momento más adecuado para administrarlo. Por ejemplo, Nazario y colaboradores (27) administraron sofosbuvir y simeprevir en cualquier momento, antes o después de la diálisis, y lograron una RVS12 en el 100\% de los pacientes. No se documentaron EAM durante el tratamiento en el $76 \%(13 / 17)$ de los pacientes. Los EAM reportados fueron insomnio (12\%), náuseas (5\%), cefalea $(5 \%)$ y anemia (5\%) (27).

En términos de efectividad, los AAD presentaron RVS12 entre el $83,3 \%$ y $100 \%$ de la población estudiada, mostrando altas tasas de curación en los pacientes tratados con estos esquemas. En el caso de sofosbuvir, Bhamidimarri y colaboradores (36), aun utilizando dosis ajustadas del medicamento, lograron una RVS12 del 83,3\% (10/12) en pacientes de HD y DP; mientras que en los pacientes con TFG entre $8-15 \mathrm{~mL} / \mathrm{min}$ alcanzaron una RVS12 del $100 \%(3 / 3)$.

En relación con la seguridad, varios de los EAM reportados en los estudios para los diferentes fármacos pueden estar asociados con la alta prevalencia de comorbilidades como hipertensión arterial, diabetes mellitus y enfermedad cardiovascular en pacientes de edad avanzada con ERC, especialmente en diálisis.

La presente revisión estructurada ofrece información sistematizada sobre las pautas de $\mathrm{AAD}$ utilizadas en pacientes de edad avanzada con HC y ERC, especialmente en la práctica clínica habitual, que mostraron ser efectivas y seguras en los pacientes tratados. Dicha información puede fortalecer los procesos de prescripción y seguimiento farmacoterapéutico $y$, de esta manera, contribuir a la efectividad y seguridad del tratamiento.

Considerando que el sofosbuvir es uno de los medicamentos más utilizados, puesto que inhibe la replicación de múltiples genotipos del VHC, tiene una alta barrera genética a la resistencia, una buena tolerabilidad y un potencial limitado de interacciones medicamento-medicamento (46); 
se podría considerar la administración de la dosis completa ( $400 \mathrm{mg}$ cada 24 horas) en pacientes de edad avanzada, con ERC estadios 4 y 5 , incluidos aquellos en HD o DP, específicamente cuando no esté disponible ninguno de los esquemas que se eliminan por vía hepática (elbasvir/grazoprevir, paritaprevir/ombitasvir/ritonavir/dasabuvir, daclatasvir/ asunaprevir), o cuando estén contraindicados, por ejemplo, en pacientes con cirrosis descompensada (Child-Pugh B o C) en quienes no está indicado el uso de elbasvir/grazoprevir ni de paritaprevir/ombitasvir/ritonavir/dasabuvir.

Dado que, hasta el momento de esta revisión, las guías de práctica clínica (nacionales e internacionales) no recomiendan el uso de esquemas que contengan sofosbuvir en pacientes con ERC estadios 4 o 5, incluido ERCT, las recomendaciones de la presente revisión deben ser consideradas con cautela. Por tanto, la decisión de tratar la HC en pacientes de edad avanzada con ERC, especialmente estadios 4 y 5 , debe ser individualizada, considerando los medicamentos disponibles, los riesgos y beneficios previstos del tratamiento, la esperanza de vida del paciente y sus comorbilidades. En caso de decidir la utilización de AAD, deben realizarse los debidos ajustes de dosis y un seguimiento cuidadoso de la función renal, de la aparición de EAM y de la RVS.

De igual manera, se resalta la necesidad de contar con estudios prospectivos de seguridad y efectividad de los $\mathrm{AAD}$ en el tratamiento del VHC en pacientes de edad avanzada con ERC.

\section{LIMITACIONES}

Esta revisión presenta varias limitaciones y la información debe interpretarse con cautela por los prescriptores. Por una parte, la búsqueda solo se realizó en la base de datos PubMed/Medline y, por lo general, la recomendación en este tipo de trabajos es realizar la búsqueda en dos o más bases de datos. Sin embargo, la revisión de las referencias de los artículos incluidos pudo atenuar esta limitación. Por otra parte, los artículos revisados incluían información de pacientes de varios grupos etarios, en la mayoría de los casos, sin clasificar los datos según la edad, por lo que no fue posible extraer la información exclusiva de dosificación y eficacia de los pacientes con edades iguales o superiores a los 65 años. A pesar de esto, los estudios revisados muestran la utilización de los $\mathrm{AAD}$ en dicho grupo etario, lo que podría indicar la ausencia de problemas con su utilización.

Adicionalmente, ninguno de los artículos revisados incluyó información para los pacientes con edad igual o superior a los 80 años. En consecuencia, no es posible hacer recomendaciones firmes con respecto al tratamiento en esta población.

\section{Agradecimientos}

Al grupo de investigación Promoción y Prevención Farmacéutica de la Universidad de Antioquia, Medellín, Colombia.

\section{Financiación}

Ninguna.

\section{Conflicto de intereses}

Los autores declaran no tener ningún conflicto de intereses.

\section{REFERENCIAS}

1. Hajarizadeh B, Grebely J, Dore GJ. Epidemiology and natural history of HCV infection. Nat Rev Gastroenterol Hepatol. 2013;10(9):553-62. doi: 10.1038/nrgastro.2013.107.

2. Kohli A, Shaffer A, Sherman A, Kottilil S. Treatment of hepatitis C: a systematic review. JAMA. 2014;312(6):63140. doi: 10.1001/jama.2014.7085.

3. Park H, Adeyemi A, Henry L, Stepanova M, Younossi Z. A meta-analytic assessment of the risk of chronic kidney disease in patients with chronic hepatitis $\mathrm{C}$ virus infection. J Viral Hepat. 2015;22(11):897-905. doi: 10.1111/jvh.12413.

4. Chen YC, Lin HY, Li CY, Lee MS, Su YC. A nationwide cohort study suggests that hepatitis $\mathrm{C}$ virus infection is associated with increased risk of chronic kidney disease. Kidney Int. 2014;85(5):1200-7. doi: 10.1038/ki.2013.455.

5. Li WC, Lee YY, Chen IC, Wang SH, Hsiao CT, Loke SS. Age and gender differences in the relationship between hepatitis $\mathrm{C}$ infection and all stages of Chronic kidney disease. J Viral Hepat. 2014;21(10):706-15. doi: 10.1111/jwh.12199.

6. Kurbanova N, Qayyum R. Association of Hepatitis C Virus Infection with Proteinuria and Glomerular Filtration Rate. Clin Transl Sci. 2015;8(5):421-4. doi: 10.1111/cts.12321.

7. American Association for the Study of Liver Diseases and the Infectious Diseases Society of America. Patients with Renal Impairment. AASLD [Internet]. 2017 [acceso el 26 de agosto de 2017]. Disponible en: http://www.hcvguidelines.org/unique-populations/renal-impairment.

8. Blé M, Aguilera V, Rubín A, García-Eliz M, Vinaixa C, Prieto $\mathrm{M}$, et al. Improved renal function in liver transplant recipients treated for hepatitis $\mathrm{C}$ virus with a sustained virological response and mild chronic kidney disease. Liver Transpl. 2014;20(1):25-34. doi: 10.1002/lt.23756.

9. Beinhardt S, Al Zoairy R, Ferenci P, Kozbial K, Freissmuth C, Stern R, et al. DAA-based antiviral treatment of patients with chronic hepatitis $\mathrm{C}$ in the pre- and postkidney transplantation setting. Transpl Int. 2016;29(9):999-1007. doi: $10.1111 /$ tri. 12799.

10. Hsu YC, Lin JT, Ho HJ, Kao YH, Huang YT, Hsiao NW, et al. Antiviral treatment for hepatitis $\mathrm{C}$ virus infection is associated with improved renal and cardiovascular outcomes in 
diabetic patients. Hepatology. 2014;59(4):1293-302. doi: 10.1002/hep. 26892 .

11. Sorbera MA, Friedman ML, Cope R. New and emerging evidence on the use of second-generation direct acting antivirals for the treatment of hepatitis $\mathrm{C}$ virus in renal impairment. J Pharm Pract. 2017;30(3):359-365. doi: 10.1177/0897190016632128.

12. Bunchorntavakul C, Maneerattanaporn M, Chavalitdhamrong D. Management of patients with hepatitis $\mathrm{C}$ infection and renal disease. World J Hepatol. 2015;7(2):213-25. doi: 10.4254/wjh.v7.i2.213.

13. Suda G, Kudo M, Nagasaka A, Furuya K, Yamamoto Y, Kobayashi T, et al. Efficacy and safety of daclatasvir and asunaprevir combination therapy in chronic hemodialysis patients with chronic hepatitis C. J Gastroenterol. 2016;51(7):733-40. doi: 10.1007/s00535-016-1162-8.

14. Grimaldi V, Sommese L, Picascia A, Casamassimi A, Cacciatore F, Renda A, et al. Association between human leukocyte antigen class I and II alleles and hepatitis $\mathrm{C}$ virus infection in high-risk hemodialysis patients awaiting kidney transplantation. Hum Immunol. 2013;74(12):1629-32. doi: 10.1016/j.humimm.2013.08.008.

15. Chebrolu P, Colombo RE, Baer S, Gallaher TR, Atwater $\mathrm{S}$, Kheda $\mathrm{M}$, et al. Bacteremia in hemodialysis patients with hepatitis C. Am J Med Sci. 2015;349(3):217-21. doi: 10.1097/MAJ.0000000000000391.

16. Toyoda H, Kumada T, Tada T, Takaguchi K, Ishikawa T, Tsuji K, et al. Safety and efficacy of dual direct-acting antiviral therapy (daclatasvir and asunaprevir) for chronic hepatitis $\mathrm{C}$ virus genotype 1 infection in patients on hemodialysis. J Gastroenterol. 2016;51(7):741-7. doi: 10.1007/s00535016-1174-4.

17. Lin MV, Sise ME, Pavlakis M, Amundsen BM, Chute $\mathrm{D}$, Rutherford AE, et al. Efficacy and Safety of Direct Acting Antivirals in Kidney Transplant Recipients with Chronic Hepatitis C Virus Infection. PLoS One. 2016;11(7):e0158431. doi: 10.1371/journal.pone.0158431.

18. Millet Torres D, Curbelo Rodríguez L, Ávila Riopedre F, Benítez Méndez M, Prieto García F. Overall outcomes in kidney transplant recipients with hepatitis $\mathrm{C}$ in a district hospital in Camagüey, Cuba. Nefrologia. 2015;35(5):50911. doi: 10.1016/j.nefro.2015.06.003.

19. Center for Disease Analysis. Hepatitis C prevalence [Internet]. 2012 [acceso el 19 de febrero de 2017]. Disponible en: http://www.centerforda.com/HepC/ HepMap.html.

20. Instituto Nacional de Salud. Informe del comportamiento en la notificación de los eventos hepatitis B, C y coinfección/suprainfección hepatitis B/delta hasta período epidemiológico VI. Colombia: Instituto Nacional de Salud; 2017.

21. Levey AS, Coresh J. Chronic kidney disease. Lancet. 2012;379(9811):165-80. doi: 10.1016/S01406736(11)60178-5.

22. Chen YC, Chiou WY, Hung SK, Su YC, Hwang SJ. Hepatitis $\mathrm{C}$ virus itself is a causal risk factor for chronic kidney disease beyond traditional risk factors: a 6-year nationwide cohort study across Taiwan. BMC Nephrol. 2013;14:187. doi: 10.1186/1471-2369-14-187.

23. ElDesoky ES. Pharmacokinetic-pharmacodynamic crisis in the elderly. Am J Ther. 2007;14(5):488-98. doi: 10.1097/01. mjt.0000183719.84390.4d.

24. Salvi F, Marchetti A, D>Angelo F, Boemi M, Lattanzio F, Cherubini A. Adverse drug events as a cause of hospitalization in older adults. Drug Saf. 2012;35 Suppl 1:29-45. doi: 10.1007/BF03319101.

25. Moorman AC, Tong X, Spradling PR, Rupp LB, Gordon $\mathrm{SC}, \mathrm{Lu} \mathrm{M}$, et al. Prevalence of Renal Impairment and Associated Conditions Among HCV-Infected Persons in the Chronic Hepatitis Cohort Study (CHeCS). Dig Dis Sci. 2016;61(7):2087-93. doi: 10.1007/s10620-016-4199-x.

26. Stark JE, Cole J. Successful treatment of chronic hepatitis C virus infection in a patient receiving daily peritoneal dialysis. Am J Health Syst Pharm. 2017;74(19):1541-1544. doi: 10.2146/ajhp160729.

27. Nazario HE, Ndungu M, Modi AA. Sofosbuvir and simeprevir in hepatitis $C$ genotype 1-patients with end-stage renal disease on haemodialysis or GFR $<30 \mathrm{ml} / \mathrm{min}$. Liver Int. 2016;36(6):798-801. doi: 10.1111/liv.13025.

28. Hidalgo-Collazos P, Marín-Ventura L, Sánchez R, García-López L, Criado-Illana MT. Tratamiento de la infección por virus de la hepatitis C en hemodiálisis. Nefrologia. 2014;34(1):132-3. doi: 10.3265/Nefrologia.pre2013.Sep.12268.

29. Roth D, Nelson DR, Bruchfeld A, Liapakis A, Silva M, Monsour H Jr, et al. Grazoprevir plus elbasvir in treatmentnaive and treatment-experienced patients with hepatitis $\mathrm{C}$ virus genotype 1 infection and stage 4-5 chronic kidney disease (the C-SURFER study): a combination phase 3 study. Lancet. 2015;386(10003):1537-45. doi: 10.1016/ S0140-6736(15)00349-9.

30. Roche Farma S.A. COPEGUS ${ }^{\circledast}$ (ribavirin) Tablets FDA [Internet]. 2011 [acceso el 27 de noviembre de 2017]. Disponible en: https://www.accessdata.fda.gov/drugsatfda_docs/label/2011/021511s023lbl.pdf.

31. UpToDate Inc. Drug information [Internet]. [acceso el 9 de noviembre de 2017]. Disponible en: https://www.uptodate.com/contents/search.

32. Truven Health Analytics. Dosing \& therapeutic tools database. IBM [internet] [acceso el 9 de noviembre de 2017]. Disponible en: https://www.micromedexsolutions.com.

33. Hundemer GL, Sise ME, Wisocky J, Ufere N, Friedman LS, CoreyKE, et al. Use of sofosbuvir-based direct-acting antiviral therapy for hepatitis $\mathrm{C}$ viral infection in patients with severe renal insufficiency. Infect Dis (Lond). 2015;47(12):924-9. doi: 10.3109/23744235.2015.1078908.

34. Sperl J, Frankova S, Senkerikova R, Neroldova M, Hejda V, Volfova M, et al. Relevance of low viral load in haemodialysed patients with chronic hepatitis $\mathrm{C}$ virus infection. World J Gastroenterol. 2015;21(18):5496-504. doi: 10.3748/wjg. v21.i18.5496.

35. Saxena V, Koraishy FM, Sise ME, Lim JK, Schmidt M, Chung $\mathrm{RT}$, et al. Safety and efficacy of sofosbuvir-containing regimens 
in hepatitis C-infected patients with impaired renal function. Liver Int. 2016;36(6):807-16. doi: 10.1111/liv.13102.

36. Bhamidimarri KR, Czul F, Peyton A, Levy C, Hernandez M, Jeffers L, et al. Safety, efficacy and tolerability of halfdose sofosbuvir plus simeprevir in treatment of Hepatitis $\mathrm{C}$ in patients with end stage renal disease. J Hepatol. 2015;63(3):763-5. doi: 10.1016/j.jhep.2015.06.004.

37. Polepally AR, Badri PS, Eckert D, Mensing S, Menon RM. Effects of mild and moderate renal impairment on ombitasvir, paritaprevir, ritonavir, dasabuvir, and ribavirin pharmacokinetics in patients with chronic HCV infection. Eur J Drug Metab Pharmacokinet. 2017;42(2):333-339. doi: 10.1007/s13318-016-0341-6.

38. Gopalakrishnan SM, Polepally AR, Mensing S, Khatri A, Menon RM. Population Pharmacokinetics of Paritaprevir, Ombitasvir, and Ritonavir in Japanese Patients with Hepatitis C Virus Genotype 1b Infection. Clin Pharmacokinet. 2017;56(1):1-10. doi: 10.1007/s40262-016-0423-2.

39. Pockros PJ, Reddy KR, Mantry PS, Cohen E, Bennett M, Sulkowski MS, et al. Efficacy of Direct-Acting Antiviral Combination for Patients With Hepatitis C Virus Genotype 1 Infection and Severe Renal Impairment or End-Stage Renal Disease. Gastroenterology. 2016;150(7):1590-8. doi: 10.1053/j.gastro.2016.02.078.

40. Martin P, Gane E, Ortiz-Lasanta G, Liu L, Sajwani K, Kirby B, et al. Safety and Efficacy of Treatment With Daily Sofosbuvir $400 \mathrm{mg}$ + Ribavirin $200 \mathrm{mg}$ for 24 Weeks in Genotype 1 or 3 HCV-Infected Patients With Severe Renal Impairment. Boston: 66th Annual Meeting of the American Association for the Study of Liver Diseases [Internet];
2015 [acceso el 29 de septiembre de 2017]. Disponible en: http://www.natap.org/2015/AASLD/AASLD_134.htm.

41. Brennan BJ, Wang K, Blotner S, Magnusson MO, Wilkins JJ, Martin P, et al. Safety, tolerability, and pharmacokinetics of ribavirin in hepatitis $\mathrm{C}$ virus-infected patients with various degrees of renal impairment. Antimicrob Agents Chemother. 2013;57(12):6097-105. doi: 10.1128/AAC.00608-13.

42. Hassan Q, Roche B, Buffet C, Bessede T, Samuel D, Charpentier B, et al. Liver-kidney recipients with chronic viral hepatitis $\mathrm{C}$ treated with interferon-alpha. Transpl Int. 2012;25(9):941-7. doi: 10.1111/j.14322277.2012.01520.x

43. Kojima A, Kakizaki S, Hosonuma K, Yamazaki Y, Horiguchi $\mathrm{N}$, Sato K, et al. Interferon treatment for patients with chronic hepatitis $\mathrm{C}$ complicated with chronic renal failure receiving hemodialysis. J Gastroenterol Hepatol. 2013;28(4):690-9. doi: $10.1111 /$ jgh.12118.

44. Perumpail RB, Wong RJ, Ha LD, Pham EA, Wang U, Luong $\mathrm{H}$, et al. Sofosbuvir and simeprevir combination therapy in the setting of liver transplantation and hemodialysis. Transpl Infect Dis. 2015;17(2):275-8. doi: 10.1111/tid.12348.

45. Gilead Sciences Inc. SOVALDI ${ }^{\circledR}$ (sofosbuvir) tablets, for oral use. FDA [internet]. 2017 [acceso el 3 de noviembre de 2017]. Disponible en: https://www.gilead.com/ /media/ Files/pdfs/medicines/liver-disease/sovaldi/sovaldi_pi.pdf.

46. Yau AH, Yoshida EM. Hepatitis C drugs: the end of the pegylated interferon era and the emergence of all-oral interferon-free antiviral regimens: a concise review. Can J Gastroenterol Hepatol. 2014;28(8):445-51. 